\title{
DIFFERENT VOLUMES AND CONCENTRATIONS IN FIXED DOSES OF BUPIVACAINE IN LUMBOSACRAL EPIDURAL IN RELATION TO CRANIAL SPREAD IN LIVE DOGS
}

\section{RAFAEL DEROSSI ${ }^{1 *}$, LARISSA CORREA HERMETO ${ }^{2}$, PAULO HENRIQUE DE AFFONSECA JARDIM ${ }^{1}$, LUCAS LATTA ESCOBAR ${ }^{3}$, PEDRO HENRIQUE NAVARETTE MENEZES ${ }^{3}$}

${ }^{1}$ Department of Veterinary Medicine-Surgery and Anesthesiology, Faculty of Veterinary Medicine and Animal Science, Federal University of Mato Grosso do Sul, Caixa Postal 549, Campo Grande, MS, CEP 79070-900, Brazil. ${ }^{2}$ Department of Veterinary Medicine, Postgraduate Program in Veterinary Sciences, Faculty of Veterinary Medicine and Animal Science, Federal University of Mato Grosso do Sul, Campo Grande, Brazil. ${ }^{3}$ Department of Veterinary Medicine, Faculty of Veterinary Medicine and Animal Science, Federal University of Mato Grosso do Sul, Campo Grande, Brazil. Email: rafael.rossi@ufms.br

Received: 11 May 2018, Revised and Accepted: 31 June 2018

ABSTRACT

Objective: The objective of this study was to assess whether the volume or concentration of local anesthetic influences its spread and quality of lumbosacral epidural blockade when the total drug dose is fixed.

Methods: A total of 30 healthy bitches, undergoing elective ovariohysterectomy received a lumbosacral epidural block with a fixed dose of 0.5 mg/kg b.w. bupivacaine after general anesthesia induction with propofol. Treatment 1 group (low volume, high concentration [LVHC], $\mathrm{n}=15$ ) received $0.2 \mathrm{~mL} / \mathrm{kg}$ b.w. of $0.25 \%$ bupivacaine, whereas treatment 2 group (high volume, low concentration [HVLC], $\mathrm{n}=15$ ) received $0.3 \mathrm{ml} / \mathrm{kg}$ b.w. of $0.167 \%$ bupivacaine. Both solutions contained radio-opaque dye. Heart rate, blood pressure, respiratory rate, rectal temperature, cranial spread, first analgesic rescue, and motor blockade were determined at predetermined intervals.

Results: At $5 \mathrm{~min}$, the dorsal cranial spread levels of bupivacaine confirmed by radiographic examination were T8 (T1-T10) for HVLC treatment and T8 (T6-T10) for LVHC treatment ( $\mathrm{p}=0.957)$. However, there was a significant difference ( $\mathrm{p}=0.029)$ in the ventral spread levels between HVLC treatment (T2; C7-T6) and LVHC treatment (T6; T5-T11). The first analgesic rescue was needed after $249 \pm 58$ min in the LVHC treatment group and after $179 \pm 32$ min in the HVLC treatment group $(\mathrm{p}=0.0005)$.

Conclusion: It was concluded, if the total dose is fixed, then administration of an HVLC bupivacaine local anesthetic solution in the lumbosacral epidural space seems to produce effective post-operative analgesia for ovariohysterectomy surgery in bitches.

Keyword: Lumbosacral epidural, Bupivacaine, Post-operative analgesia, Cranial spread, Dogs.

(C) 2018 The Authors. Published by Innovare Academic Sciences Pvt Ltd. This is an open access article under the CC BY license (http://creativecommons. org/licenses/by/4. 0/) DOI: http://dx.doi.org/10.22159/ajpcr.2018.v11i9.27254

\section{INTRODUCTION}

Lumbosacral epidural blockades are commonly used for anesthesia/ analgesia in small animals for surgical procedures of the hind limbs and abdomen. Among the advantages of these blockades are reductions in pain perception during the intraoperative period, elimination of skeletal muscle tone, and decrease in anesthetics requirements [1]. However, several factors can influence the quality of these anesthetic techniques including dose of the local anesthetic, additives such as epinephrine or hyaluronidase, $\mathrm{pH}$ adjustment and carbonation, baricity, temperature, mixtures of local anesthetics, and pregnancy [2-4]. Although it is a widely used technique, a single dose of local anesthetics administered epidurally provides a short duration of analgesia [3,5]. The total dose of local anesthetic (volume and concentration) will determine the spread and quality of the blockade. Large volumes and higher concentrations of local anesthetics produce faster onset and more effective block. Although these effects are known, the results of studies comparing volume and concentration of local anesthetics are controversial [6-9]. The administration of large volumes (0.22-0.33 mL/kg b.w.) and high concentrations $(0.75 \%)$ of bupivacaine into the subarachnoid space of sheep and monkeys has produced spinal cord injuries [10]. One study suggests that the administration of $0.75 \%$ ropivacaine into the lumbar epidural space of dogs produces a higher rate of complete anesthesia than does $0.5 \%$ ropivacaine in a similar volume $(0.22 \mathrm{~mL} / \mathrm{kg}$ b.w.) [11]. High local anesthetic concentrations are more important than dose in terms of the development of neurotoxicity [12-14]. Another factor that is not very clear is whether the volume/concentration relationship affects the cranial spread of epidural anesthesia when the total drug dose is fixed [15-17]. Few studies regarding the relative effects of volume and concentration of local anesthetic solutions used for lumbosacral epidural anesthesia/analgesia in live dogs are available. Even fewer studies exist regarding the spread of local anesthetics into the epidural space in live dogs and the related analgesic duration.

We conducted a randomized, prospective, observer-blinded study to demonstrate the spread of epidurally administered local anesthetic using radiographic assessment and to compare analgesic durations between high volume/low concentration (HVLC) and low volume/ high concentration (LVHC) bupivacaine when a constant dose was administered to bitches undergoing ovariohysterectomy (OVH).

\section{METHODS}

\section{Animals}

After obtaining approval from the University Ethical Committee and Veterinary Hospital of the Faculty of Veterinary Medicine and Animal Science, we obtained informed written consent from the owners. The bitches were brought to the veterinary hospital by their owners to be spayed. Before enrollment in the study, owners were informed about the method of analgesia and motor assessments. A total of 30 bitches with ages ranging between 2 and 6 years, weights of $>8$ or $<13 \mathrm{~kg}$, and American Society of Anesthesiologists physical status I for elective $\mathrm{OVH}$ were included in the study. Bitches were excluded if there was any contraindication to epidural anesthesia, pregnancy, 
obesity, or known systemic diseases. The animals were received the day before the anesthetic and surgical procedures and kept in individual cages at the laboratory for anesthesia and surgery of Small Animals. Animals received no food at night but had free access to water until $1 \mathrm{~h}$ before premedication. A single operator was involved in all $\mathrm{OVH}$ procedures, which were performed using a routine method through a midline approach and three-hemostat technique; the procedure did not take longer than $60 \mathrm{~min}$. Surgery was allowed to begin 15-20 min after performing the epidural block to wait for the latency period of bupivacaine [18].

\section{Experimental design}

Before premedication (basal), heart rate (HR), arterial blood pressure (systolic [SAP], diastolic [DAP], and mean [MAP] arterial pressure), respiratory rate (RR), and rectal temperature (RT) were measured. Arterial blood pressures were measured with a multivariable analyzer (Dixtal DX 2021; Dixtal Biomédica Ind. e Com., Ltd., Manaus, Brazil) using a non-invasive device, with the cuff (width, 11.7-6.9 cm or 15$8.9 \mathrm{~cm}$ ) placed over the ulnar artery on the forearm. HR was measured using electrocardiography, RR was determined as the number of chest movements counted over $1 \mathrm{~min}$, and RT was obtained with a digital thermometer at baseline. Post-operative pain was assessed using a score composed of physiologic and behavioral parameters based on previous studies that evaluated post-operative pain in small animals [19-22]; the usual precautions were taken by the same blinded researcher. The bitches were evaluated for motor blockade by the presence or absence of pelvic limb weakness. The degrees of muscular relaxation of the abdominal wall and relaxation of the ovarian ligaments during surgery were evaluated by the same blinded surgeon using the following scale:1, without any degree of relaxation of the musculature of the abdominal wall or ovarian ligaments; 2 , moderate degree of relaxation of the abdominal wall muscles, but without relaxation of the ovarian ligaments; 3 , moderate degree of relaxation of the abdominal wall muscles and of the ovarian ligaments; and 4, intense relaxation of the abdominal wall muscles and of the ovarian ligaments. Other effects such as sialorrhea, nausea, and vomiting were also observed during the experimental period.

\section{Anesthetic protocol}

All animals involved in all experiments were premedicated with intramuscular (IM) acepromazine $0.05 \mathrm{mg} / \mathrm{kg}$ b.w. (acepran $0.2 \%$; Univet S.A., São Paulo, Brazil). After premedication, an intravenous catheter (22 G) was inserted into the cephalic vein to infuse lactated Ringer's solution at a rate of $10 \mathrm{~mL} / \mathrm{kg} / \mathrm{h}$ during the surgical period. All anesthetic procedures were performed by two trained veterinary anesthetist researchers. After premedication (15 $\mathrm{min})$, anesthesia was induced with propofol (4-6 mg/kg b.w.; provive 1\%; Claris Injectable Ltd., Ahmedabad, India), which was slowly administered by an intravenous catheter previously placed. When anesthesia was considered inadequate (increase in SAP, DAP, MAP, HR, or RR of $>15 \%$ and somatic responses such as voluntary gross movements of the forelimbs and head or swallowing), then a bolus (1 mg/kg b.w., IV) was administered as needed. After induction of general anesthesia and endotracheal intubation, the animals were mechanically ventilated with oxygen to maintain end-tidal $\mathrm{CO}_{2}$.

\section{Epidural procedures and radiographic images}

The bitches were given a lumbosacral epidural injection of one of two anesthetic treatments by random allocation. All lumbosacral epidural blocks were performed by a researcher who was not involved in the subsequent management of the patient. After identifying the lumbosacral space (L7-S1), this area was clipped and cleaned in an aseptic manner. A lumbosacral epidural injection was performed by a blinded veterinarian for all bitches using an 18-G or 20-G Tuohy needle (Perican; B Braun, São Gonzalo, Brazil) with the bevel directed cranially; the drugs were injected slowly at a rate of $1 \mathrm{~mL}$ every $3 \mathrm{~s}$. Insertion into the epidural space was confirmed through the use of the hanging drop method and loss of resistance by injected air $(0.5 \mathrm{~mL})$. The bitches received a fixed dose $(0.5 \mathrm{mg} / \mathrm{kg}$ b.w.) of bupivacaine (Neocaína $0.25 \%$;
Cristália Chemical and Pharmaceutical Products, Itapira, Brazil) of either $0.2 \mathrm{~mL} / \mathrm{kg}$ b.w. of $0.25 \%$ (LVHC treatment, $\mathrm{n}=15$ ) or $0.3 \mathrm{~mL} / \mathrm{kg}$ b.w. of $0.167 \%$ (HVLC treatment, $\mathrm{n}=15$ ) containing $300 \mathrm{mg} / \mathrm{mL}$ diluted radio-opaque dye (Omnipaque; GE Healthcare Co., Ltd., Xangai, China). The $0.167 \%$ concentration was prepared by diluting $0.25 \%$ plain bupivacaine with normal saline without preservatives. The bitch was then immediately placed in the right lateral position for radiographic examination. For all radiographic procedures, the animals were kept in the same position. The extent of the drugs into the epidural space was from the injection point (L7=1), and the cranial spread was toward C7 (cervical 7=21), as demonstrated in Fig. 1.

Radiographic images of the cervical-sacral area were saved, and the spread levels were determined by an independent radiologist blinded to the protocol; the mean of the dorsal and ventral spread was presented as a number corresponding to a vertebra or fractions of a vertebra. HR, RR, non-invasive arterial blood pressure (SAP, DAP, and MAP), and RT were monitored and recorded throughout the total intravenous anesthesia (TIVA), epidural injections, and surgery at $\mathrm{T}_{0}, 15 \mathrm{~min}$ after premedication $\left(\mathrm{T}_{15}\right)$, after TIVA $\left(\mathrm{T}_{20}\right)$, after epidural injections $\left(\mathrm{T}_{30}\right)$, $60 \mathrm{~min}$ after epidural injections $\left(\mathrm{T}_{60}\right)$, and $120 \mathrm{~min}$ after epidural injections $\left(\mathrm{T}_{120}\right)$.

\section{Assessment of post-operative pain}

Approximately $1 \mathrm{~h}$ after epidural injections (after surgery and at the end of anesthesia) were administered, blinded measurements of postoperative pain and motor strength in the hind limbs were recorded by one of the researches in the recovery room. The end of anesthesia was considered to have occurred when the animals were able to stand and walk normally. Duration of post-operative analgesia was measured using a multidimensional composite pain scale of $0-18$, where a score of 0 represents a total lack of physiologic/behavior indicative of pain and 18 is the worst pain imaginable (Table 1). After the epidural injections, the assessments were performed at 2, 4, and $6 \mathrm{~h}$ and until the end of effective analgesia; during this period, the animals were maintained in the recovery room in individual cages. Rescue morphine $(0.5 \mathrm{mg} / \mathrm{kg}$ b.w. IM) was administered if there was a score $\geq 6$ during the observation period.

\section{Rescue analgesia}

The end of the motor blockade was defined as the time from when the bitches entered the recovery room until when they managed to remain standing and normally walk inside and outside of the cage. The time to the first rescue with IM morphine (post-operative analgesia duration) was defined as the time from the end of the surgeries until the first registration of a score $\geq 6$. The discharge criteria were assessed after the first rescue analgesic, when the bitches were conscious, had the ability to drink water and eat, and had no side effects. Discharge time was defined as the time from when the bitches entered the recovery room until discharge to home.

\section{Statistical analysis}

Statistical analysis was performed with the Statistical Analysis System software for Windows (SAS ${ }^{\circledR}$ 9.2). Quantitative variables were analyzed

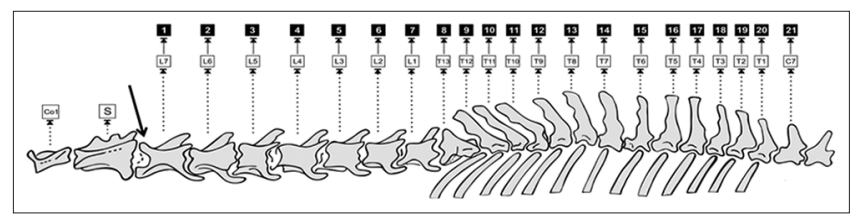

Fig. 1: Drawing of the spine to demonstrate cranial propagation of anesthetic solution into the epidural space to correlate the vertebrae, with numbers for statistical analysis. Black arrow indicates the insertion point of the epidural needle. Co: Coccygeal vertebrae; S: Sacral vertebrae; L: Lumbar vertebrae; T: Thoracic vertebrae; and C: Cervical vertebra. Numbers (black square) are corresponding with the vertebrae indicated by the respective arrows 
within and among groups using analysis of variance for repeated measures and the post hoc Tukey method was applied. The maximal spread value of the selected vertebral area was expressed as mean \pm standard deviation (SD), and the Wilcoxon rank sum test was used to analyze the number of segments with vertebral spreading. Differences between the treatments were analyzed using the Student's $t$-test, followed by the Mann-Whitney rank sum test when appropriate. For all measurements, mean \pm SD values or median \pm confidence intervals were determined. For all comparisons, $\mathrm{p}<0.05$ was considered statistically significant.

\section{RESULTS}

A total of 30 bitches were studied, of which 15 were administered LVHC treatment and 15 were administered HVLC treatment. There were no significant differences between the two treatments with regard to age, weight, duration of anesthesia and surgery, and fluid administration during surgery. In the recovery room, the difference in the first rescue time was found to be significantly different between the two treatments. Intravenous propofol did not differ significantly among treatments (Table 2). Two animals in each treatment group showed what appeared to be Schiff-Sherrington syndrome (increased reflex excitability of the front limbs caused by block of spinal impulses to hind part of body) during the administration of epidural injections that lasted for a few min. Motor blockade has twice the duration for LVHC treatment ( $85 \mathrm{~min} ; \mathrm{p}=0.0003$ ) than HVLC treatment (46 min). There were no epidural block failures in any patient. The degree of muscle relaxation of the abdominal wall and the ovarian pedicles was of moderate intensity (median, score 3 ) for the HVLC and LVHC treatments $(p=0.33)$ during the surgical period. Dorsal spread and ventral spread were not always equal. The dorsal cranial spread levels (median with ranges) of bupivacaine confirmed by radiographic examination were T8 (T1-T10) for HVLC treatment and T8 (T6-T10) for LVHC treatment $(p=0.957)$. However, there was a significant difference $(p=0.029)$ in the ventral spread levels between HVLC treatment (T2; C7-T6) (Fig. 2) and LVHC treatment (T6; T5-T11) (Table 3 and Fig. 3).

The HR did not change significantly in any of the treatment groups studied. Both treatment groups had changes in RR, arterial blood pressures, and RT, as shown in Table 4. RR was significantly lower with

Table 1: Multidimensional composite pain score applied to bitches after OVH

\begin{tabular}{|c|c|c|}
\hline Observation & Score & Criteria \\
\hline \multirow[t]{4}{*}{ Response to stimuli } & 0 & No response: Dog does not react when the surgical wound is touched or pressed \\
\hline & 1 & Mild response: Tense muscles and dog moves slowly when the surgical wound is touched \\
\hline & 2 & $\begin{array}{l}\text { Moderate response: Tense muscles and dog turns head and licks before or after touch or pressure of the surgical } \\
\text { wound }\end{array}$ \\
\hline & 3 & $\begin{array}{l}\text { Severe response: Dog is restless, reacts quickly, and acts aggressively toward the evaluator when the wound is } \\
\text { touched or pressed }\end{array}$ \\
\hline \multirow[t]{3}{*}{ Movement } & 0 & Normal posture: Standing has head hanging down and moves spontaneously inside and outside the cage \\
\hline & 1 & Dogs in sternal or lateral recumbency or abnormal posture (prayer position and hunched) \\
\hline & 2 & Dog does not move after being stimulated, inside or outside the cage \\
\hline \multirow[t]{4}{*}{ Vocalization } & 0 & Not vocalizing \\
\hline & 1 & Vocalizing when touched by the evaluator \\
\hline & 2 & Intermittent vocalization when stimulated by the evaluator \\
\hline & 3 & Continuous spontaneous vocalization without being manipulated \\
\hline \multirow[t]{3}{*}{ Behavioral } & 0 & Dog is submissive and interested in the environment and is friendly when stimulated by the evaluator \\
\hline & 1 & Slow reaction, wary; dog is not interested in the environment and does not interact with the evaluator \\
\hline & 2 & Aggressive when handled or when stimulated by the evaluator \\
\hline \multirow[t]{3}{*}{ Return of appetite } & 0 & Eats normally during the post-operative period \\
\hline & 1 & Eats less during the post-operative period \\
\hline & 2 & Dog is not interested in food during the post-operative period \\
\hline \multicolumn{3}{|r|}{ о } \\
\hline \multirow[t]{3}{*}{$\mathrm{HR}$} & 0 & Normal $(70-120$ beats/min) \\
\hline & 1 & $\geq 20 \%$ above the values of the pre-operative period \\
\hline & 2 & $\geq 50 \%$ above the values of the pre-operative period \\
\hline \multirow[t]{3}{*}{$\mathrm{RR}$} & 0 & Normal (15-35 breaths/min) \\
\hline & 1 & $\geq 20 \%$ above the values of the pre-operative period \\
\hline & 2 & $\geq 50 \%$ above the values of the pre-operative period \\
\hline \multirow[t]{2}{*}{ Mydriasis } & 0 & No \\
\hline & 1 & Yes \\
\hline \multirow[t]{2}{*}{ RT } & 0 & Within the reference range \\
\hline & 1 & Above or below the reference range \\
\hline
\end{tabular}

The maximum possible score (greatest pain) was 18. Score 0 indicates no pain, scores of 1-6 indicate mild pain, scores of 7-12 indicate moderate pain, scores of 13-18 indicate severe pain. Additional analgesics were given to dogs with a score $\geq 6$. OVH: Ovariohysterectomy, RT: Rectal temperature, RR: Respiratory rate, HR: Heart rate

Table 2: Demographic data and clinical variables

\begin{tabular}{lll}
\hline Characteristics & HVLC treatment (n=15) & LVHC treatment (n=15) \\
\hline Age (y) & $4 \pm 1.2$ & $4.3 \pm 1.0$ \\
Weight (kg) & $10 \pm 2.0$ & $8.9 \pm 1.5$ \\
Volume injected (mL/kg) & $3.1 \pm 0.6$ & $1.8 \pm 0.4$ \\
Dose total of propofol (mg) & $59.8 \pm 12.4$ & $64 \pm 9.5$ \\
Duration (min) & $28 \pm 8.8$ & $28.1 \pm 4.4$ \\
Surgical time & $46 \pm 13$ & $8.080^{\mathrm{a}}$ \\
Motor blockade & $179 \pm 32$ & $0.0001^{\mathrm{a}}$ \\
First analgesic rescue & $3 \pm 0.5$ & $249 \pm 58$ \\
Discharge time (h) & $4 \pm 1$ \\
\hline
\end{tabular}

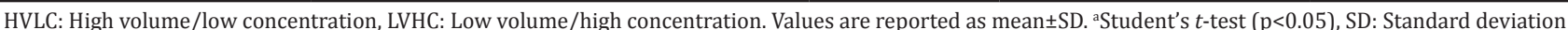




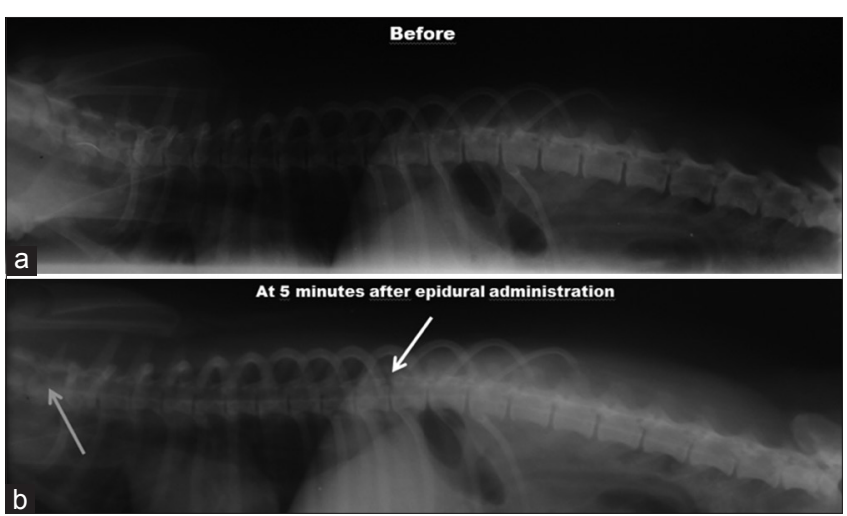

Fig. 2: X-ray shows the animal before the epidural injection (a) and the cranial spread level 5 min after epidural injection of high volume/low concentration treatment (b). White arrow indicates the cranial spread of the dorsal surface; gray arrow indicates the cranial spread of the ventral surface of the spinal canal with the solution containing diluted radio-opaque dye
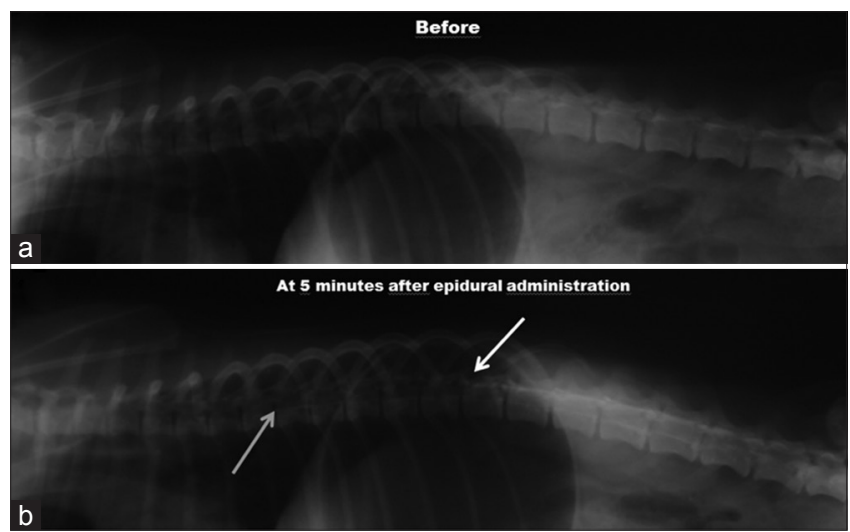

Fig. 3: X-ray shows the animal before the epidural injection (a) and the cranial spread level $5 \mathrm{~min}$ after epidural injection of low volume/high concentration treatment (b). White arrow indicates the cranial spread of the dorsal surface; gray arrow indicates the cranial spread of the ventral surface of the spinal canal with solution containing diluted radio-opaque dye

LVHC and HVLC treatments at 10-30 min. The blood arterial pressures decreased significantly with both treatments. LVHC treatment significantly decreased SAP at 10-60 min, DAP at 20-30 min, and MAP at 10-120 min. HVLC treatment significant decreased SAP and MAP at 10-120 min and DAP at 10-30 min. RT was significantly decreased in both treatment groups at 20-120 min. Four dogs in the HVLC treatment group and five in the LVHC treatment group had vomiting during the immediate post-operative period.

\section{DISCUSSION}

Both treatment groups had cranial spread into the epidural space, and the HVLC treatment group showed more cranial extent than the LVHC treatment group. Cranial migration of the local anesthetic solutions was determined by radiographic examination in individual bitches of this study; when volume was increased $0.2-0.3 \mathrm{~mL} / \mathrm{kg}$ b.w., a higher level of blocked dermatomes from T6 to T2 was produced. In both treatment groups, there was difference between the dorsal and ventral surfaces of the epidural space. These variations may be due to the position of the body of the animal, anatomical factors, and the positive pressure caused by the volume injected just after the epidural injections [23-25]. A study involving anesthetized dogs showed that epidural administration of methylene blue and iohexol with a volume of $0.2 \mathrm{~mL} / \mathrm{kg}$ b.w. reached the cranial level T4-L4 after $5 \mathrm{~min}$ and had maximal spread at approximately
20-25 min (T2-L4 and C6-L3, respectively) after epidural injections [25]. The resulting change in pressure during epidural administration of local analgesics induces an increase in pressure of 5.5-6 kPa after injection, and this increase remains until baseline at the end of a 10min measurement period [24]. Radiographic examination of our study was performed 5 min after epidural injection, and change in epidural pressure was not measured. However, we believe that increased epidural pressure plays an important role in the spread of solution into the epidural space. Another factor that can influence the spread is the position of the animal during or after the epidural injection, taking into account the gravity within the epidural cavity, which is $1-2 \mathrm{~cm}$ in dogs $[23,25]$. This concept originated from the premise that the animal placed in sternal recumbency with its pelvic limbs flexed provides an upward slope between the epidural canal and lowest seventh lumbar vertebra to the highest $13^{\text {th }}$ thoracic vertebra, inhibiting the cranial spread of analgesic solutions [25]. A study involving cadaver dogs showed that contrast-enhanced comsputed tomography with a volume of $0.2 \mathrm{~mL} / \mathrm{kg}$ b.w. of iodinated radiographic contrast medium injected into the lumbosacral epidural space reaches the thoracolumbar junction in the majority of dogs [26].

The volume required for analgesia after lumbosacral epidural in dogs has been evaluated by several authors $[7,8,22,27]$. The volume per $\mathrm{kg}$ of dosage produces a narrow linear correlation with the dermatome level of the blockade [28]. Ovarian innervation and cranial abdominal wall are derived from the ovarian and renal plexus, through the hypogastric cranial and caudal (sympathetic) nerves connected to the T10 and L3 segments of the spinal cord and through the thoracic splanchnic nerves. OVH surgery is a concern among veterinarians because it requires a high level of blockade to block peritoneal stimulation arising from ovarian and ligament traction. However, large volumes of local anesthetic into the epidural space can cause serious side effects such as respiratory depression, hypotension, and bradycardia [27,29]. In our study, high volume treatment $(0.3 \mathrm{~mL})$ reached the second thoracic vertebra (T2), and at the time of traction and clamping of the ovarian ligament (between T30 and T60), no animal showed signs of discomfort or pain such as involuntary movements, hyperventilation, and increase in blood pressure and HR requiring supplementary doses of general anesthetic.

Since the 1960s, the volumes used in epidural administration in dogs were established, with $0.14 \mathrm{~mL} / \mathrm{kg}$ b.w. for the regions caudal to the perineum and $0.20 \mathrm{~mL} / \mathrm{kg}$ b.w. for regions caudal to the thoracolumbar junction $[3,30]$. Although these volumes are accepted by veterinarians, they were based on subjective clinical data rather than the actual measurement of the volume of the epidural space $[4,31,32]$. However, the consensus is that the variables that determine the quality and level of lumbosacral epidural blockade are volume, dose, and concentration of the injected drug. In children, the rostral spread of caudal analgesia depends mainly on the volume of local anesthetic injected [33]. In this study, bupivacaine in a fixed dose of $0.5 \mathrm{mg} / \mathrm{kg}$ b.w. $(0.167 \%$ and $0.25 \%$ ) in volumes of 0.2 and $0.3 \mathrm{~mL} / \mathrm{kg}$ b.w. provided analgesia to sacral, lumbar, lower thoracic, and midthoracic dermatomes. The assumption was that a large volume with a low concentration would keep the total mass in the epidural space with a safe margin. A study involving children demonstrated that administering a bupivacaine caudal epidural with different concentrations $(0.25 \%$ and $0.125 \%)$ was effective for producing similar post-operative analgesia, but the low concentration had less motor weakness [34]. Another advantage that was observed in this study was that the low concentration of bupivacaine $(0.167 \%)$ allowed a faster return of the motor blockade and discharge criteria earlier than in the bitches with lumbosacral epidurals that were performed with the higher concentration $(0.25 \%)$. These results are consistent with those of previous studies that demonstrated that motor blockade increased with increasing concentrations of local anesthetic $[5,17,34,35]$. In a study of caudal epidural anesthesia in children for hypospadias repair, Silvani et al. [5] demonstrated that ropivacaine with a high concentration $(0.375 \%)$ and low volume (0.5 mL/kg b.w.) had shorter post-operative analgesia (520 min) 
Table 3: Clinical and imaging characteristics for each bitch, after bupivacaine lumbosacral epidural injection of HVLC group ( $0.3 \mathrm{~mL} / \mathrm{kg}$ b.w. of $0.167 \%$ bupivacaine) or LVHC group $(0.2 \mathrm{~mL} / \mathrm{kg}$ b.w. of $0.25 \%$ bupivacaine) plus radio-opaque dye

\begin{tabular}{|c|c|c|c|c|c|c|c|}
\hline \multicolumn{8}{|c|}{ Cranial spread extend on radiographic lateral image } \\
\hline \multicolumn{4}{|c|}{ HVLC group } & \multicolumn{4}{|c|}{ LVHC group } \\
\hline Bitch* & Weight (kg) & Ventral & Dorsal & Bitch & Weight (kg) & Ventral & Dorsal \\
\hline 1 & 9.1 & T1 & T11 & 1 & 8.4 & T5 & T6 \\
\hline 2 & 9 & T1 & $\mathrm{T} 10$ & 2 & 8.8 & T9 & T8 \\
\hline 3 & 9.3 & T5 & L1 & 3 & 10.5 & T2 & T10 \\
\hline 4 & 12.5 & T3 & Т9 & 4 & 10.9 & T3 & T13 \\
\hline 5 & 13 & T2 & T13 & 5 & 10 & $\mathrm{~T} 2$ & $\mathrm{~T} 2$ \\
\hline 6 & 12 & $\mathrm{~T} 1$ & T3 & 6 & 8.7 & T3 & T3 \\
\hline 7 & 8.4 & T6 & T8 & 7 & 9.9 & L3 & T10 \\
\hline 8 & 11.7 & T2 & T10 & 8 & 11.2 & L4 & T5 \\
\hline 9 & 11.9 & T5 & T10 & 9 & 8.4 & T3 & T5 \\
\hline 10 & 11 & T3 & T6 & 10 & 8 & T10 & T9 \\
\hline 11 & 8.7 & $\mathrm{~T} 1$ & $\mathrm{~T} 4$ & 11 & 9.5 & T3 & T9 \\
\hline 12 & 10.4 & $\mathrm{~T} 2$ & $\mathrm{~T} 4$ & 12 & 11 & T8 & T10 \\
\hline 13 & 10.9 & T1 & T7 & 13 & 8.6 & $\mathrm{~T} 4$ & T6 \\
\hline 14 & 8.2 & C7 & T11 & 14 & 10.8 & T6 & T3 \\
\hline 15 & 9.6 & T3 & T9 & 15 & 12.5 & T7 & T12 \\
\hline
\end{tabular}

*All bitches were neutered, T - Thoracic vertebra, C - Cervical vertebra, L - Lumbar vertebra, HVLC: High volume/low concentration

Table 4 Cardiovascular and respiratory values and rectal temperature in bitches undergoing ovariohysterectomy (OVH) (n=15/group) receiving either $0.2 \mathrm{ml} / \mathrm{kg}$ b.w. bupivacaine $0.25 \%$ (LVHC group; low volume/high concentration) or $0.3 \mathrm{ml} / \mathrm{kg}$ b.w. bupivacaine $0.167 \%$ (HVLC group; high volume/low concentration)

\begin{tabular}{|c|c|c|c|c|c|c|}
\hline \multirow[t]{2}{*}{ Groups } & \multicolumn{6}{|c|}{ Time (min) } \\
\hline & T0 & $\mathrm{T} 10$ & T20 & T30 & T60 & T120 \\
\hline \multicolumn{7}{|l|}{$\mathrm{HR}$} \\
\hline HVLC & $116 \pm 6$ & $117 \pm 6$ & $113 \pm 7$ & $104 \pm 6$ & $126 \pm 8$ & $121 \pm 5$ \\
\hline \multicolumn{7}{|l|}{$\mathrm{RR}$} \\
\hline LVHC & $34 \pm 3$ & $24 \pm 2^{*}$ & $24 \pm 2^{*}$ & $22 \pm 2 *$ & $22 \pm 4$ & $24 \pm 2$ \\
\hline HVLC & $45 \pm 9$ & $36 \pm 7^{*}$ & $33 \pm 5^{*}$ & $30 \pm 5^{*}$ & $39 \pm 5$ & $32 \pm 2$ \\
\hline \multicolumn{7}{|l|}{ SAP } \\
\hline LVHC & $137 \pm 4$ & $115 \pm 4^{*}$ & $98 \pm 2 *$ & $91 \pm 3^{*}$ & $94 \pm 7^{*}$ & $116 \pm 7$ \\
\hline HVLC & $132 \pm 4$ & $103 \pm 5^{*}$ & $95 \pm 4^{*}$ & $86 \pm 2 *$ & $96 \pm 7^{*}$ & $112 \pm 8^{*}$ \\
\hline \multicolumn{7}{|l|}{ DAP } \\
\hline LVHC & $78 \pm 5$ & $72 \pm 4$ & $57 \pm 4^{*}$ & $55 \pm 4 *$ & $67 \pm 7$ & $80 \pm 6$ \\
\hline HVLC & $86 \pm 6$ & $59 \pm 7^{*}$ & $61 \pm 5^{*}$ & $49 \pm 3^{*}$ & $73 \pm 7$ & $74 \pm 7$ \\
\hline \multicolumn{7}{|l|}{ MAP } \\
\hline LVHC & $105 \pm 4$ & $90 \pm 3^{*}$ & $76 \pm 2 *$ & $71 \pm 3^{*}$ & $82 \pm 6^{*}$ & $115 \pm 6$ \\
\hline HVLC & $105 \pm 4$ & $79 \pm 5^{*}$ & $76 \pm 4^{*}$ & $66 \pm 2 *$ & $77 \pm 6^{*}$ & $90 \pm 7^{*}$ \\
\hline \multicolumn{7}{|l|}{ RT } \\
\hline LVHC & $38.7 \pm 0.1$ & $38.6 \pm 0.1$ & $37.8 \pm 0.1^{*}$ & $36.8 \pm 0.1^{*}$ & $35.4 \pm 0.2^{*}$ & $37.2 \pm 0.2^{*}$ \\
\hline HVLC & $38.6 \pm 0.1$ & $38.4 \pm 0.1$ & $37.7 \pm 0.1^{*}$ & $36.7 \pm 0.2^{*}$ & $35.4 \pm 0.2^{*}$ & $37.0 \pm 0.2^{*}$ \\
\hline
\end{tabular}

T0, indicates basal, before premedication, $\mathrm{T}_{10}, 10 \mathrm{~min}$ after premedication, $\mathrm{T}_{20}, 20 \mathrm{~min}$ after $\mathrm{TIVA}, \mathrm{T}_{30}, 30$ min after epidural injections, $\mathrm{T}_{60}, 60$ min after epidural injections, $\mathrm{T}_{120}, 120 \mathrm{~min}$ after epidural injections, HR: Heart rate (beats/min), RR: Respiratory rate (breaths/min), SAP: Systolic arterial pressure (mmHg); DAP: Diastolic arterial pressure (mmHg), MAP: Mean arterial pressure $(\mathrm{mmHg})$, RT: Rectal temperature $\left({ }^{\circ} \mathrm{C}\right) .{ }^{*}$ Significantly different $(\mathrm{p}<0.05)$ from baseline. Values are reported as mean \pm SD. SD: Standard deviation

than ropivacaine with a low concentration $(0.1 \%)$ and high volume (1.8 $\mathrm{mL} / \mathrm{kg}$ b.w.; $950 \mathrm{~min})$. However, the findings indicated a longer duration of post-operative analgesia with LVHC treatment (249 $\mathrm{min})$ than with HVLC treatment (179 $\mathrm{min})$. These differences probably occurred because of the type of local anesthetic used, concentrations and volumes, site of epidural administration, and type of surgical procedure. Although post-operative analgesia time is less with HVLC treatment, it had the same effectiveness as LVHC treatment for blocking the peritoneal response during ovarian and ovarian ligaments traction, with no change in the quality of post-operative analgesia.

This study showed that there was a significant decrease in blood pressure regardless of the higher level of HVLC treatment when compared with LVHC treatment. High epidural block (T1-T4) with $0.5 \%$ bupivacaine $(0.5-0.6 \mathrm{~mL} / \mathrm{kg}$ b.w.) induced a decrease in MAP to $52 \%$ of the control value, and this can be attributed to the interruption of preganglionic sympathetic outflow within the blockade area [29]. Both treatments used in this study showed a significant decrease in blood pressure but within the limits considered clinically viable. These effects were started at $10 \mathrm{~min}$ and may be assigned to premedication administration (acepromazine) or the administration of general anesthesia (TIVA propofol). However, we consider vasodilation of blocked regions induced by administration of epidural bupivacaine to have contributed to the extension of time in this reduction. The reduction of RT in LVHC and HVLC treatments is probably due to this vasodilation as well. The vomiting reflex is triggered by activation of chemoreceptors in the medulla oblongata located in the central nervous system; it is a protective mechanism that reacts to the ingestion of toxic compounds or toxic plasma concentrations of local anesthetic. Other adverse effects associated with epidural anesthesia (respiratory muscle paralysis, hypotension, and Schiff-Sherrington reflex) can be attributed to the spread of local anesthetic to the cervical spinal segments [3]. 
The occurrence of vomiting in the post-operative period with both treatments of our study was probably due to more cranial spread of anesthetic solutions injected into the epidural space.

\section{CONCLUSION}

Our results confirm that in bitches undergoing OVH, the spread level was T6 (T5-T11) with $0.2 \mathrm{~mL} / \mathrm{kg}$ b.w. of $0.25 \%$ bupivacaine and T2 (C7T6) with $0.3 \mathrm{~mL} / \mathrm{kg}$ b.w. of $0.167 \%$ bupivacaine when the total dose of the epidural bupivacaine $(0.5 \mathrm{mg} / \mathrm{kg}$ b.w.) was fixed. Low concentration of bupivacaine $0.167 \%$ provides adequate post-operative analgesia but with a shorter time than bupivacaine $0.25 \%$ and fewer motor effects. Both treatments had significant cardiovascular and respiratory alterations, but they were within an acceptable range in these clinically healthy bitches. Further studies involving bitches are needed to evaluate other factors shown to have an effect on spread of epidural injectable blockade, including age and obesity.

\section{ACKNOWLEDGMENTS}

The authors thank the radiologists, Dr. Paulo A.T. Andreussi and Dr. Desireé R. de Oliveira, for evaluation of the radiographs. The authors also express gratitude to Dr. Breno F.B. Sampaio, for his assistance with statistical analysis of the data.

\section{AUTHOR'S CONTRIBUTIONS}

Rafael Derossi has provided the study design, study execution, interpretation, and preparation of the manuscript. Larissa Correa Hermeto performed all surgical procedures, study execution, and data analysis. Paulo H.A. Jardim, preparation of drugs and performing of the epidural anesthesia. Lucas Latta Escobar evaluated post-operative pain, data collection, study execution, and data analysis. Pedro H. Navarette Menezes, data collection, study execution, and data analysis.

\section{CONFLICTS OF INTEREST}

The authors declare that there are no conflicts of interest regarding this paper.

\section{REFERENCES}

1. Valverde A. Epidural analgesia and anesthesia in dogs and cats. Vet Clin North Am Small Anim Pract 2008;38:1205-30, 5 .

2. Bromage PR. Mechanism of action of extradural analgesia. $\mathrm{Br} \mathrm{J}$ Anaesth 1975;47 suppl:199-211.

3. Skarda RT, Tranquilli WJ. Local and regional anesthetic and analgesic techniques: Dogs. In: Tranquilli WJ, Thurmon JC, Grimm KA, editors. Lumb and Jones' Veterinary Anesthesia and Analgesia. $4^{\text {th }}$ ed. Ames, IA: Blackwell Publishing; 2007. p. 575-80.

4. DeRossi R, de Barros AL, Silva-Neto AB, Pompermeyer CT, Frazílio FO. Hyaluronidase shortens levobupivacaine lumbosacral epidural anaesthesia in dogs. J Small Anim Pract 2011:52:195-9.

5. Silvani P, Camporesi A, Agostino MR, Salvo I. Caudal anesthesia in pediatrics: An update. Minerva Anestesiol 2006;72:453-9.

6. Feldman HS, Covino BG. Comparative motor-blocking effects of bupivacaine and ropivacaine, a new amino amide local anesthetic, in the rat and dog. Anesth Analg 1988;67:1047-52.

7. Franquelo C, Toledo A, Manubens J, Cristòfol C, Arboix M. Bupivacaine disposition and pharmacologic effects after intravenous and epidural administrations in dogs. Am J Vet Res 1995;56:1087-91.

8. Hendrix PK, Raffe MR, Robinson EP, Felice LJ, Randall DA. Epidural administration of bupivacaine, morphine, or their combination for postoperative analgesia in dogs. J Am Vet Med Assoc 1996;209:598-607.

9. Kona-Boun JJ, Cuvelliez S, Troncy E. Evaluation of epidural administration of morphine or morphine and bupivacaine for postoperative analgesia after premedication with an opioid analgesic and orthopedic surgery in dogs. J Am Vet Med Assoc 2006;229:1103-12.

10. Rosen MA, Baysinger CL, Shnider SM, Dailey PA, Norton M, Curtis JD, et al. Evaluation of neurotoxicity after subarachnoid injection of large volumes of local anesthetic solutions. Anesth Analg 1983;62:802-8

11. Duke T, Caulkett NA, Ball SD, Remedios AM. Comparative analgesic and cardiopulmonary effects of bupivacaine and ropivacaine in the epidural space of the conscious dog. Vet Anaesth Analg 2000;27:13-21.

12. Ready LB, Plumer MH, Haschke RH, Austin E, Sumi SM. Neurotoxicity of intrathecal local anesthetics in rabbits. Anesthesiology 1985;63:364-70

13. Malinovsky JM, Pinaud M. Neurotoxicity of agents administered by intrathecal route. Neurotoxicité des agents administrés par voie intrathécale. Ann FranAnesth Réanimat 1996;15:647-58.

14. Hodgson PS, Neal JM, Pollock JE, Liu SS. The neurotoxicity of drugs given intrathecally (spinal) Anesth Analg 1999;88:797-809.

15. Whiteside R, Jones D, Bignell S, Lang C, Lo SK. Epidural ropivacaine with fentanyl following major gynaecological surgery: The effect of volume and concentration on pain relief and motor impairment. Br J Anaesth 2000;84:720-4.

16. Dernedde M, Stadler M, Bardiau F, Boogaerts J. Comparison of different concentrations of levobupivacaine for post-operative epidural analgesia. Acta Anaesthesiol Scand 2003;47:884-90.

17. Hong JY, Han SW, Kim WO, Cho JS, Kil HK. A comparison of high volume/low concentration and low volume/high concentration ropivacaine in caudal analgesia for pediatric orchiopexy. Anesth Analg 2009:109:1073-8

18. Torske KE, Dyson DH. Epidural analgesia and anesthesia. Vet Clin North Am Small Anim Pract 2000;30:859-74.

19. Hansen B. Through a glass darkly: Using behavior to assess pain. Semin Vet Med Surg (Small Anim) 1997;12:61-74.

20. Hellyer PW, Gaynor JS. Acute postsurgical pain in dogs and cats. Compend Contin Educ: Small Anim Pract 1998;20:140-53.

21. Brondani JT, Mama KR, Luna SP, Wright BD, Niyom S, Ambrosio J, et al. Validation of the English version of the UNESP-Botucatu multidimensional composite pain scale for assessing postoperative pain in cats. BMC Vet Res 2013;9:143-58.

22. DeRossi R, Hermeto LC, Marques BC, Jardim PH. Postoperative analgesic effects of epidural administration of methadone, tramadol, or nalbuphine in ovariohysterectomized dogs. Asian J Anim Vet Adv 2015;10:782-0.

23. Jones RS. Epidural analgesia in the dog and cat. Vet J 2001;161:123-31.

24. Iff I, Moens Y, Schatzmann U. Use of pressure waves to confirm the correct placement of epidural needles in dogs. Vet Rec 2007;161:22-5.

25. Son WG, Kim J, Seo JP, Yoon J, Choi M, Lee LY, et al. Cranial epidural spread of contrast medium and new methylene blue dye in sternally recumbent anaesthetized dogs. Vet Anaesth Analg 2011;38:510-5.

26. Kawalilak LT, Tucker RL, Greene SA. Use of contrast-enhanced computed tomography to study the cranial migration of a lumbosacral injectate in cadaver dogs. Vet Radiol Ultrasound 2015;56:570-4

27. Freire CD, Torres ML, Fantoni DT, Cavalcanti RL, Noel-Morgan J. Bupivacaine $0.25 \%$ and methylene blue spread with epidural anesthesia in dog. Vet Anaesth Analg 2010;37:63-9.

28. Takasaki M, Dohi S, Kawabata Y, Takahashi T. Dosage of lidocaine for caudal anesthesia in infants and children. Anesthesiology 1977:47:527-9.

29. Greitz T, Andreen M, Irestedt L. Haemodynamics and oxygen consumption in the dog during high epidural block with special reference to the splanchnic region. Acta Anaesthesiol Scand 1983;27:211-7.

30. Klide AK. Epidural analgesia in the dog and cat. J Am Vet Med Assoc 1969;153:165-73

31. Lebeaux MI. Experimental epidural anaesthesia in the dog with lignocaine and bupivacaine. Br J Anaesth 1973;45:549-55.

32. Popilskis S, Kohn DF, Laurent L, Danilo P. Efficacy of epidural morphine versus intravenous morphine for post-thoractotomy pain in dogs. Vet Anaesth Analg 1993;20:21-5.

33. Armitage EN. Caudal block in children. Anaesthesia 1979;34:396

34. Wolf AR, Valley RD, Fear DW, Roy WL, Lerman J. Bupivacaine for caudal analgesia in infants and children: The optimal effective concentration. Anesthesiology 1988;69:102-6.

35. Feldman HS, Dvoskin S, Arthur GR, Doucette AM. Antinociceptive and motor-blocking efficacy of ropivacaine and bupivacaine after epidural administration in the dog. Reg Anesth 1996;21:318-26. 